\title{
Violência doméstica contra a mulher: estudo em uma metrópole da Amazônia
}

\author{
Maria Célia Guimarães Borges ${ }^{1}$ \\ Milene Miranda Lucas² \\ Paulo Sérgio Lima da Silva ${ }^{3}$ \\ Rita de Cássia Barbosa dos Santos ${ }^{4}$
}

\section{Resumo}

O estudo aborda o fenômeno da violência doméstica e familiar contra a mulher na cidade de Belém/PA, a partir do perfil das mulheres atendidas, no período de 2008 a 2017, pela Casa Abrigo Emanuelle Rendeiro Diniz. Objetiva socializar o conhecimento, subsidiando as ações para o enfrentamento dessa expressão da "questão social". A abordagem é quanti-qualitativa, com análise de dados sistematizados pela vigilância socioassistencial, com aporte teórico em autores centrais. A maioria das mulheres são negras, não possuem renda e residem em áreas periféricas da cidade. Daí a importância de apreensão desta realidade considerando a relação classe, gênero e raça.

\section{Palavras-Chave}

Gênero; Violência doméstica e familiar; Política de Assistência Social.

Domestic violence against women: a study in an Amazon metropolis

\begin{abstract}
The study addresses the phenomenon of domestic and family violence against women in the city of Belém / PA, based on the profile of women assisted, from 2008 to 2017, by Casa Abrigo Emanuelle Rendeiro Diniz. It aims to socialize knowledge, subsidizing actions to face this expression of the "social issue". The approach is quanti-qualitative, with analysis of data systematized by socio-assistance surveillance, with theoretical input from central authors. Most of the women are black, have no income and live in peripheral areas of the city. Therefrom the importance of understanding this reality considering the relationship between class, gender and race.
\end{abstract}

Keywords

Genre; Domestic and family violence; Social Assistance Policy. 


\section{Introdução}

A política social e os padrões de proteção social devem ser compreendidos no contexto da sociedade burguesa, assumindo particularidades conforme o tempo histórico e a correlação de forças no âmbito do Estado. É neste contexto que se compreende a constituição da Política Nacional de Assistência Social - PNAS, no Brasil. No município de Belém, o órgão gestor da Assistência Social é a Fundação Papa João XXIII - FUNPAPA, organizada de acordo com o Sistema Único de Assistência Social - SUAS. Dessa forma, a vigilância socioassistencial ${ }^{5}$ assume papel de extrema importância na produção, sistematização e análise de informações com vias ao fortalecimento da função protetiva da Política Municipal de Assistência Social.

Este artigo socializa os resultados da investigação realizada pelo Setor de Vigilância Socioassistencial - SEVISA e a equipe técnica da Casa Abrigo Emanuelle Rendeiro Diniz - CAERD, ambos da FUNPAPA. A pesquisa foca o perfil das mulheres vítimas de violência doméstica atendidas na CAERD e tem uma abordagem quanti-quali, as quais, segundo Minayo (2010, p. 76), "não são incompativeis e podem ser integradas [...] os estudos quantitativos e qualitativos, quando feitos em conjunto, promovem uma mais elaborada e completa construção da realidade". As estratégias metodológicas adotadas foram a revisão bibliográfica e documental. Em seguida realizou-se a sistematização e análise de informações contidas em 490 prontuários ${ }^{6}$ de mulheres em situação de violência doméstica, atendidas no período de 2008 a $2017^{7}$, para assim discutir criticamente o fenômeno da violência doméstica e familiar contra a mulher, na cidade de Belém/PA, em suas múltiplas determinações, objetivando, sobretudo, fortalecer a rede protetiva das mulheres em situação de violência doméstica.

\section{A violência contra a mulher: notas críticas}

A violência contra a mulher é um fenômeno que perpassa por outros e para compreendê-lo é preciso atentar para desigualdades, discursos 
de poder, ideologias, linguagens, manifestações culturais e históricas. A análise torna-se mais límpida quando se parte da categoria Gênero que, gestada no interior dos movimentos feministas, tem como uma de suas signifıcações a construção social dos sexos. A argumentação exclusivamente biológica para as desigualdades entre homens (macho) e mulheres (fêmea) dá lugar à análise da dimensão histórico-cultural visceralmente presente na constituição das identidades dos sujeitos. Lima (2018, p. 188) afırma que "ao falarmos de relações de gênero, estamos nos referindo às relações sociais estabelecidas entre os sexos e aos significados atribuídos a ele". Ao discutir que essas relações são socialmente construídas, Saffioti (2004, p. 35) expõe que as mulheres são "socializadas para desenvolver comportamentos dóceis, cordatos, apaziguadores".

A construção histórica e social apresenta o "homem típico", o exemplar da espécie humana, cujo temperamento deveria ser pautado, por exemplo, pela robustez, valentia, uma agressividade inata e capacidade de comando. Saffioti (1999, p. 83), tendo por base a compreensão da violência contra a mulher como expressão do patriarcado e incorporando também às suas reflexões o conceito de "gênero", contribuiu de forma decisiva para a definição das diversas formas de violência contra a mulher. A autora destaca a violência familiar como sendo aquela que envolve membros de uma mesma família extensa ou nuclear, levando-se em conta a consanguinidade e a afınidade. Compreendida na violência de gênero, a violência familiar pode ocorrer no interior do domicílio ou fora dele, embora seja mais frequente o primeiro caso; a violência intrafamiliar - extrapola os limites do domicílio; a violência doméstica apresenta pontos de sobreposição com a familiar, podendo também atingir pessoas que, não pertencendo à família, vivem, parcial ou integralmente, no domicílio do agressor, como é o caso de agregados e empregadas(os) domésticas(os) (SAFFIOTI, 1999, p. 83). Assim, "violência de gênero é o conceito mais amplo, abrangendo vítimas como mulheres, crianças e adolescentes de ambos os sexos" (SAFFIOTI, 2001, p. 115). 
Com base em Saffioti (2004), Lima (2018, p. 190) diz que as relações sociais de gênero "nas quais predominam o modelo dominante, são [...] relações patriarcais de gênero [...] nas quais o elemento dominante é o homem. Patriarcado [...] denomina o sistema de exploração-dominação que subjuga as mulheres", destaca ainda que é anterior ao capitalismo, mas nesse modo de produção que reproduz a desigualdade, essas relações se aguçam e se expressam através da violência em suas múltiplas facetas, daí a necessidade da análise a partir da perspectiva de classe e raça. Cisne e Santos (2018, p. 68) afirmam que a violência contra a mulher é resultante "de uma estruturação de relações patriarcais da sociedade. Ao mesmo tempo, dialeticamente, essa violência estrutura o patriarcado, pois diz respeito à apropriação dos corpos e da vida das mulheres em múltiplos sentidos", constituindo-se uma "violação sistemática de direitos humanos". Conforme documento elaborado pela Organização Pan-americana da Saúde - OPAS em conjunto com a Organização Mundial da Saúde - OMS (2015), a violência praticada pelo parceiro íntimo é a forma mais comum de violência enfrentada pelas mulheres, então “o lugar supostamente seguro, idealizado como um espaço por excelência de amor, proteção e acolhimento é, muitas vezes, lócus privilegiado da violência contra a mulher" (CISNE; SANTOS, 2018, p. 69).

Dada a dimensão dialética das sociedades, as mulheres sempre se organizaram por meio dos movimentos sociais e outras estratégias de resistência e enfrentamento. Sobre esse aspecto, ao estudar esse fenômeno é importante não perceber a mulher como "ser passivo" e "anulado" dentro de uma relação conjugal. Esse viés retiraria da mulher a capacidade de construir sua autonomia, daí falar-se em “mulher em situação de violência”. Assim, com o processo de luta dos movimentos sociais feministas tem-se o avanço de legislações, equipamentos públicos de denúncias de violência contra a mulher, tem-se ainda o acúmulo teórico acerca do debate.

No contexto de conquistas dos movimentos sociais, no Brasil, a partir de 1985, criam-se as Delegacias Especializadas de Aten- 
dimento à Mulher - DEAMs. No Pará, a primeira DEAM instalada foi em Belém, em 1987. Em 2003, criou-se a Secretaria Especial de Políticas para Mulheres da Presidência da República - SPM, e a Política Nacional de Enfrentamento à Violência contra as Mulheres, que definem ações articuladas entre os poderes da República e entes federativos. Em que pese a importância dos equipamentos públicos especializados, o grande marco da luta pelo direito das mulheres no Brasil é a criação da Lei 11.340, de 07 de agosto de 2006, mais conhecida como Lei Maria da Penha (TOLOSA, 2017), que define, entre outros aspectos, as principais formas de violência doméstica e familiar contra a mulher: violência física, psicológica, sexual, patrimonial e moral.

A Lei do Feminicídio constitui outro instrumento legal para o combate à violência contra a mulher. Mesmo diante de avanços no tocante aos mecanismos legais de proteção a mulher, segundo o Atlas da Violência 2018, produzido pelo Instituto de Pesquisa Econômica Aplicada - IPEA e pelo Fórum Brasileiro de Segurança Pública - FBSP, registrou-se em 2016 um total de 4.645 mulheres assassinadas no país, o que representa uma taxa de 4,5 homicídios para cada 100 mil brasileiras. Indica também os três estados com maiores taxas, a saber: Roraima (10), Pará $(7,2)$ e Coiás $(7,1)$. Em termos absolutos, foram 294 mulheres assassinadas no estado do Pará em 2016. A análise por capitais revela que Belém, em 2013, possuía uma taxa de 5,6 homicídios por 100 mil mulheres, superior à taxa nacional $(4,8)$. Em que pese a implementação desses importantes instrumentos legais, os dados brasileiros sobre violência contra a mulher são alarmantes, o que demonstra que apenas o aparato normativo não é suficiente, é necessário construir relações sociais igualitárias pautadas em justiça social, na qual o ser humano seja o centro, o que no âmbito da sociedade capitalista não é possível em virtude da essência desta organização social baseada na relação antagônica capital/trabalho. 
Análise do perfil das mulheres em situação de violência na Casa Abrigo Emanuelle Rendeiro Diniz - CAERD

A Casa Abrigo Emanuelle Rendeiro Diniz - CAERD ${ }^{9}$, criada em 1997, é resultado das lutas empreendidas pelas organizações de mulheres de Belém/PA ${ }^{10}$ que, na década de 80 , diante do alto índice de denúncias, bem como as diversas situações de vulnerabilidades sociais que permeavam o cotidiano das mulheres vítimas de violências domésticas, intensificaram suas reinvindicações em prol da criação de Políticas Públicas que pudessem garantir ações concretas e capazes de responder importantes necessidades de um contingente de mulheres em situação de violência.

Com a instituição em 2005 do SUAS, a CAERD passa a constituir um serviço da Proteção Social de alta complexidade, tipificado nacionalmente como Serviço de Acolhimento Institucional para muIheres em situação de violência doméstica, que reafirma por finalidade o acolhimento provisório para mulheres acompanhadas ou não de seus filhos, em situação de risco de morte ou ameaça em razão da violência doméstica e familiar, causadora de lesão, sofrimento físico, sexual, psicológico ou dano moral. Compreende-se que um dos elementos para o enfrentamento da violência contra a mulher é a produção do conhecimento acerca da realidade vivenciada pelas mulheres em situação de violência doméstica, sobretudo a apreensão que esse fenômeno é constitutivo de relações sociais patriarcais, com recorte de classe e etnia, sem essa análise crítica não se constroem políticas públicas, nem tampouco outras sociabilidades. Nesta perspectiva, a seguir serão apresentados os resultados da pesquisa.

Com relação ao número de atendimentos no período de 2008 a 2017, a CAERD acolheu 490 mulheres vitimadas, perfazendo uma média anual de 49 mulheres, 605 filhos e 12 outras pessoas, totalizando 1.107 acolhidos, uma média anual de 111 pessoas. Compreende-se que a violência não se dá apenas de forma personalizada, 
haja vista atingir todo o grupo familiar, quer por sofrimento psicológico ou até mesmo físico, sendo necessário, em muitos casos, o acolhimento não apenas da mulher, mas, também, de seus filhos ou outros familiares. Analisando o perfil das mulheres, observa-se que, concernente à naturalidade, existem mulheres de 16 estados brasileiros e do Distrito Federal, entretanto, como esperado, o maior contingente é de paraenses, com 87,8\%. Dentre as 490 mulheres, $17,6 \%$ se declararam brancas, 0,4\% amarelas, 0,6\% indígenas, $11,4 \%$ negras, $63,9 \%$ pardas e $6,1 \%$ não declararam, conforme o gráfico 01. Analisando o Atlas da Violência 2018, no que concerne ao dado homicídio de mulheres segundo raça e cor, nos deparamos com a difícil realidade de que o estado do Pará se encontra em segundo lugar no ranking de homicídios de mulheres negras no país $(8,3)$, abaixo apenas do estado de Goiás $(8,5)$. Ocorre que no estado de Goiás a taxa entre as mulheres não negras é menos da metade $(4,1)$ e no estado do Pará essa taxa também é alta $(6,6)$.

\section{Distribuição das mulheres segundo cor/raça (\%)}

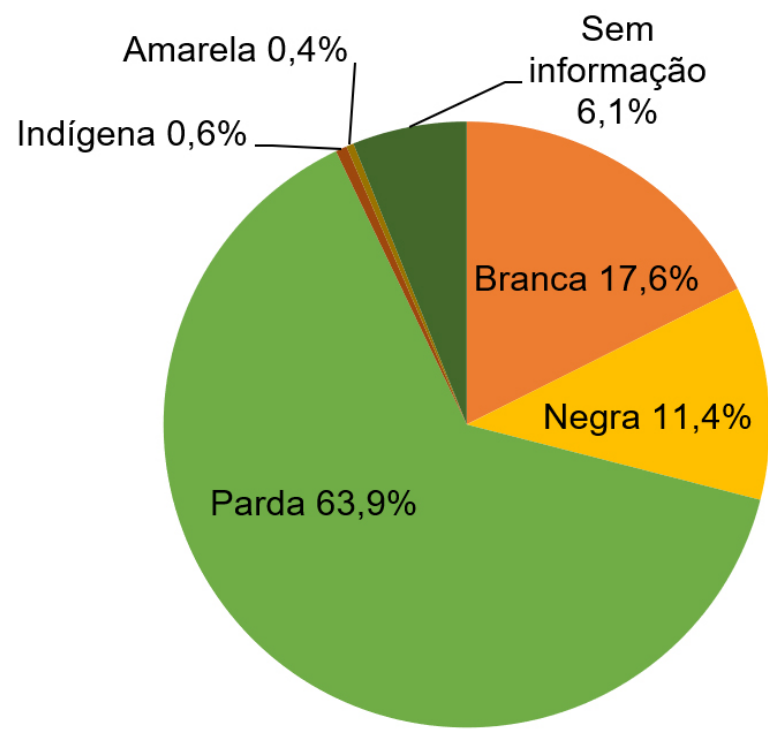

Fonte: CAERD/FUNPAPA, 2008-2017. 
Observa-se que o Atlas da Violência 2018 se utiliza de dados do IBCE, que obtém o número de mulheres negras somando as que se declaram negras com as que se declaram pardas; e o total de mulheres não negras, somando as que se declaram brancas, com as amarelas e as indígenas. Grupalizando nessas duas categorias, negras e não negras, as mulheres atendidas na CAERD, 18,6\% são não negras e 75,3\% negras. O Mapa da Violência 2018 coloca ainda que, considerando os dados de 2016, a taxa de homicídio é maior entre as mulheres negras $(5,3)$ que entre as não negras $(3,1)$, uma diferença de $71 \%$. Registra-se, assim, que com relação aos 10 anos da série 2006-2016, a taxa de homicídio para cada 100 mil mulheres negras aumentou 15,4\%, enquanto entre as não negras houve queda de $8 \%$.

Esse resultado aponta um dos elementos essenciais, pois demonstra o lugar que esta mulher ocupa na sociedade, bem como visibiliza as bases que sustentam a desigualdade de gênero. Com relação à formação sócio-histórica brasileira, Cisne e Santos (2018, p. 104) afirmam que "o racismo e o patriarcado se consolidaram como sistema, enraizaram-se na cultura, nas ideologias e religiões". As autoras continuam, "as mulheres negras ainda ocupam a base da pirâmide social: desempenham as profissões consideradas de menor prestígio; apresentam o maior índice de desemprego; e recebem os menores salários" (Plataforma Política Feminista, 2002, p. 17 apud CISNE; SANTOS, 2018, p. 114). A vulnerabilidade por renda é expressiva, tendo em vista que 42,3\% são beneficiárias do Programa Bolsa Família e 3,6\% do Benefício de Prestação Continuada, o que significa dizer que aproximadamente $46 \%$ dessas mulheres se encontravam abaixo da linha da pobreza.

Ainda nesse sentido, conforme ilustrado no gráfico $02,54,1 \%$ das mulheres não possuem renda e $23,3 \%$ vivem com menos de um salário-mínimo, sendo que, apenas, 1,6\% vivem com 03 ou mais salários-mínimos. 


\section{Gráfico 02 - Mulheres segundo a renda, em salários-mínimos (\%)}

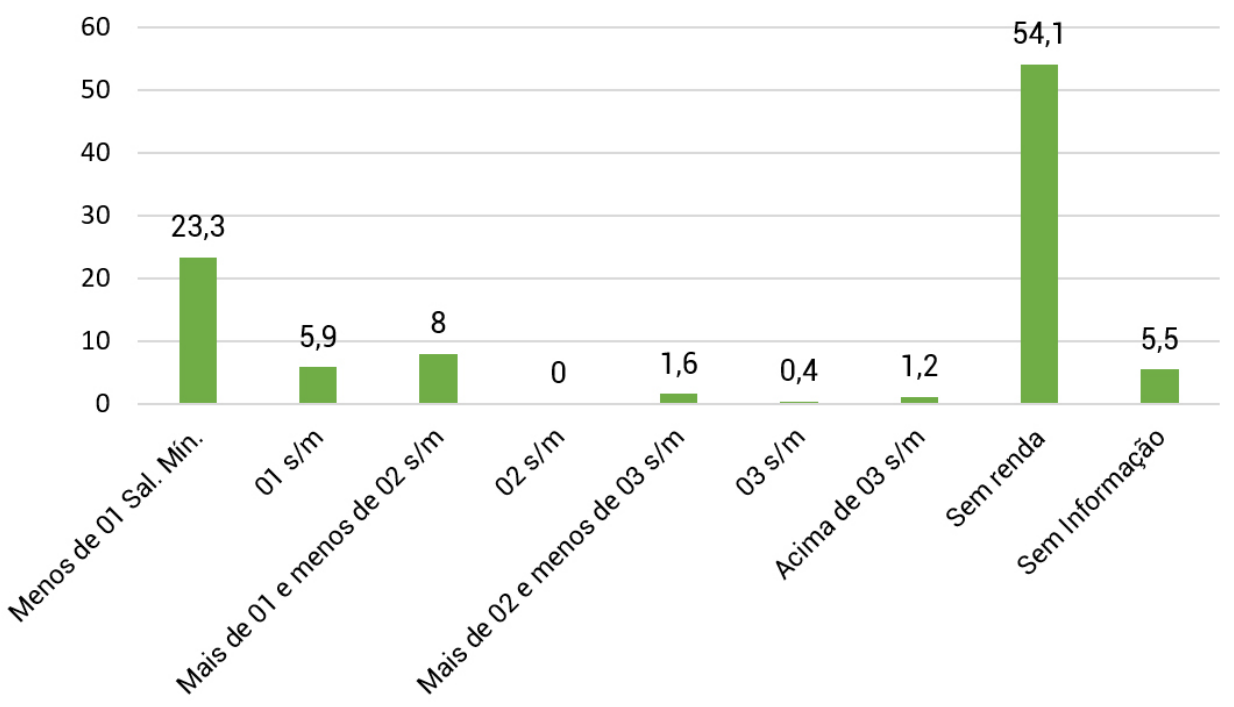

Fonte: CAERD/FUNPAPA, 2008-2017.

Jong, Sadala e Tanaka (2008) afırmam que a dependência das mulheres, em relação aos seus parceiros violentos, é uma das causas associadas ao aumento de violência familiar, principalmente em razão de grande parte das mulheres não ter emprego para sustento próprio, tornando-se submissas aos homens para manterem os fiIhos e a si. Por sua vez, mesmo as que trabalham têm suas atividades laborais prejudicadas, com a perda de produtividade, absenteísmos e até mesmo o abandono do trabalho por vergonha ou medo (ECHEVERRIA; OLIVEIRA; ERTHAL, 2017). Cabe ressaltar que na Casa Abrigo Emanuelle Rendeiro o grande contingente de mulheres acolhidas, no período ora analisado, possui baixo nível de instrução e poder aquisitivo e não conta com uma rede de proteção que as mais instruídas ou com maior poder aquisitivo contam, como o apoio familiar, o acesso a bens e serviços.

Quanto ao nível de escolaridade, chama-se atenção para alguns dados mais reveladores: o maior percentual (45,5\%) possui o ensino fundamental incompleto, $18,1 \%$ o ensino médio incompleto, $17,8 \%$ 
ensino médio completo, 7,1\% o ensino fundamental completo, 3,9\% registram ensino superior completo, 3,5\% superior incompleto, 2,7\% não constam informação e 1,4\% sem escolaridade. Dentre as profissões encontram-se as mais variadas, que vão desde advogada, assistente social, veterinária e pedagoga, bem como profissões de nível médio e fundamental. Nesse contexto, o maior percentual, 39,8\% do total, se declarou "do lar".

Observando as territorialidades de maior concentração das moradias, verifica-se que a maioria está em áreas periféricas, onde a ausência de políticas públicas torna seus dramas cotidianos mais difíceis. Ao se referir à situação da moradia, verifica-se que 50,4\% possuem casa própria, 20\% residem em casa alugada, 16,9\% em casa cedida, 5,5\% vivem de forma agregada, 0,6\% em ocupações e 0,6\% em situação de rua. $6 \%$ das mulheres não informaram sua situação de moradia.

Quanto à faixa etária, o maior quantitativo, 57\%, situa-se entre 18 a 30 anos, seguido por 40,6\% de 31 a 59 anos, 15 a 17 anos com 1,8\% e entre 60 anos ou mais com 0,6\%. Esse dado tem similaridade com os encontrados na pesquisa de Lima e Silva (2012), que investigou informações de atendimento na DEAM/Belém de 300 mulheres vítimas de violência em 2011, e revelou que 23\% estavam na faixa etária de 26 a 30 anos, os autores asseveram que essa faixa de incidência é ainda mais preocupante, considerando que a mulher é mais profissionalmente ativa e está em idade reprodutiva.

Dentre as crianças e adolescentes acompanhantes, o maior percentual (66\%) concentrou-se na faixa etária de 0 a 6 anos, primeira infância, idade em que o ser humano se encontra em fase peculiar de desenvolvimento, necessitando de atenção especial para a formação biopsicossocial, em seguida as entre 07 a 11 anos (26\%), acompanhada das entre 12 a 17 anos com 8\%. É preocupante o modelo negativo de relacionamento conjugal observado por essas crianças e adolescentes, aspecto que pode gerar um ciclo intergeracional de violência, com reprodução, pelos filhos, do comportamento violento. Soma-se a isso 
que os filhos, devido exposição a ambientes violentos, podem desenvolver problemas de adaptação social, aprendizagem e transtornos mentais (ECHEVERRIA, 2016; PEREIRA, 2017).

Do total de mulheres atendidas, apenas 31\% não trouxeram filhos. Entre as que adentraram com filhos, a maior concentração $(56,5 \%)$ está entre 01 a 02 filhos, seguidas por 12,5\%, acima de 03 filhos. Constata-se aqui um número expressivo de filhos envolvidos na violência doméstica, reproduzindo valores patriarcais, evidencia-se o quanto a violência doméstica atinge todo o grupo familiar. Salienta-se o quanto o acolhimento dos acompanhantes representa uma especificidade a mais do serviço socioassistencial e traz outros desafios técnicos e metodológicos aos profissionais da CAERD. Assim, Pereira (2017) destaca a necessidade da criação de outros serviços direcionados aos filhos de vítimas de violência doméstica, ofertando-se locais onde crianças e adolescentes recebam acompanhamento multidisciplinar.

Segundo Waters (1979, p. 88 apud CISNE; SANTOS, 2018, p. 60), "a família patriarcal monogâmica ou nuclear realiza o papel ideológico na difusão do conservadorismo ao ensinar as crianças desde a infância que devem aceitar as estruturas e premissas básicas da sociedade de classe". Compreende-se assim a reprodução social da desigualdade de gênero que se expressa nas diversas violências no âmbito da sociedade capitalista. Desse modo, a pesquisa aponta com relação à composição familiar, ilustração no gráfico 03, o maior quantitativo de mulheres vitimadas $(51,4 \%)$ compõe a família nuclear, seguida pela família extensa $(17,7 \%)$ e monoparental feminina simples $(13,7 \%)$. 
Gráfico 03 - Acolhidas segundo tipologia familiar (\%)

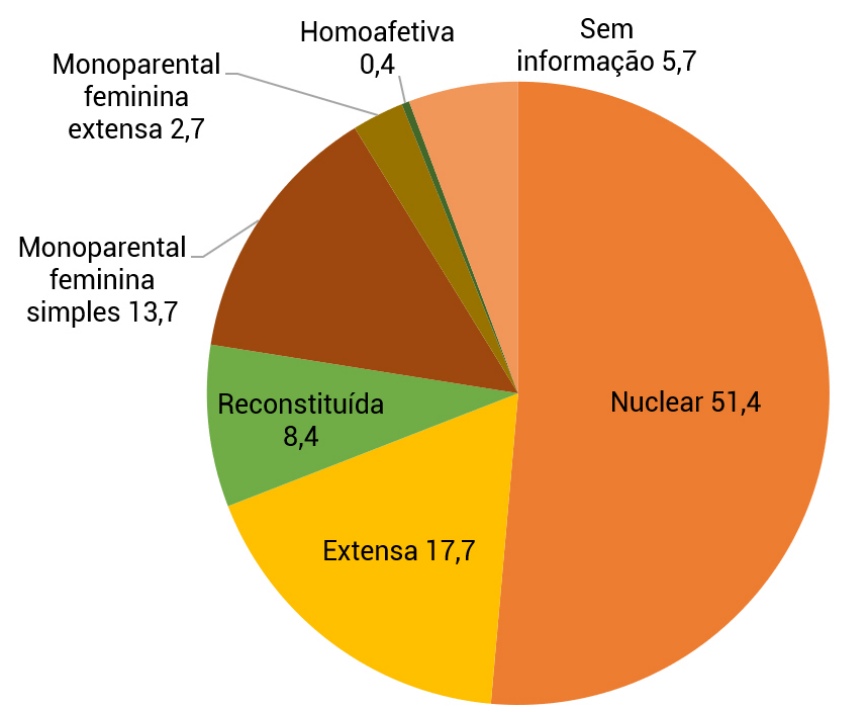

Fonte: CAERD/FUNPAPA, 2008-2017.

Segundo o IBCE (Censo 2010), a composição familiar "casal com fiIhos" está presente em 49,4\% dos lares brasileiros. Nesse sentido, as pesquisadoras Diniz, Santos e Lopes (2007) discutem o quanto as representações sociais de violência doméstica mantêm relação com concepções de família e do sentido dado ao papel do homem e da mulher no interior desse arranjo familiar. Consoante essas autoras, em muitas situações resiste a ideia de uma família nuclear que justifica e legitima a permanência de relações violentas e assimétricas, dificultando o seu rompimento. Com base em Mészáros (2002, p. 271), as autoras Cisne e Santos (2018, p. 59) afirmam que essa tipologia familiar, socialmente construída, tem o caráter "profundamente autoritária devido às funções que the são atribuídas num sistema de controle metabólico dominado pelo capital que determina a orientação de indivíduos particulares por meio de seu sistema incontestável de valores".

Com relação às principais violências sofridas, foram registrados 459 casos de violência psicológica; 398 de violência física; 358 de violência moral; 229 de violência patrimonial e 146 de violência sexual. Observa-se que, em 
muitos casos, uma única mulher foi vitimada por diferentes tipos. Assim, Lima e Silva (2012) ao analisarem dados da DEAM-Belém, indicam percentuais semelhantes entre agressões psicológicas e físicas. O crescimento no registro de casos de violência moral e patrimonial foi expressivo, com aumento de $45 \%$ e 136\%, respectivamente. A única tipologia de violência em que houve uma redução no registro de 2008 para 2017 foi a violência sexual, que reduziu em $27 \%$. Constatou-se que o local de maior incidência de violência é a residência familiar, com concentração de 56\% das ocorrências. Esse dado se contrapõe à ideia de que a família é o local mais seguro. Corroborando com essa afirmativa, o Mapa da Violência 2015 afırma que $50,3 \%$ dos assassinatos das mulheres brasileiras são cometidos por um familiar direto da mulher (7 por dia), cometidos por pessoas do círculo familiar, afetivo e dentro da própria residência. Nesse cenário, ideologicamente, a família é tida como "o lugar de aconchego e paz" (CISNE; SANTOS, 2018, p. 60), o que esconde a realidade dessa expressão da "questão social". O gráfıco 04 ilustra a realidade deste fenômeno.

Gráfico 04 - Distribuição dos locais onde ocorreu a violência (\%)

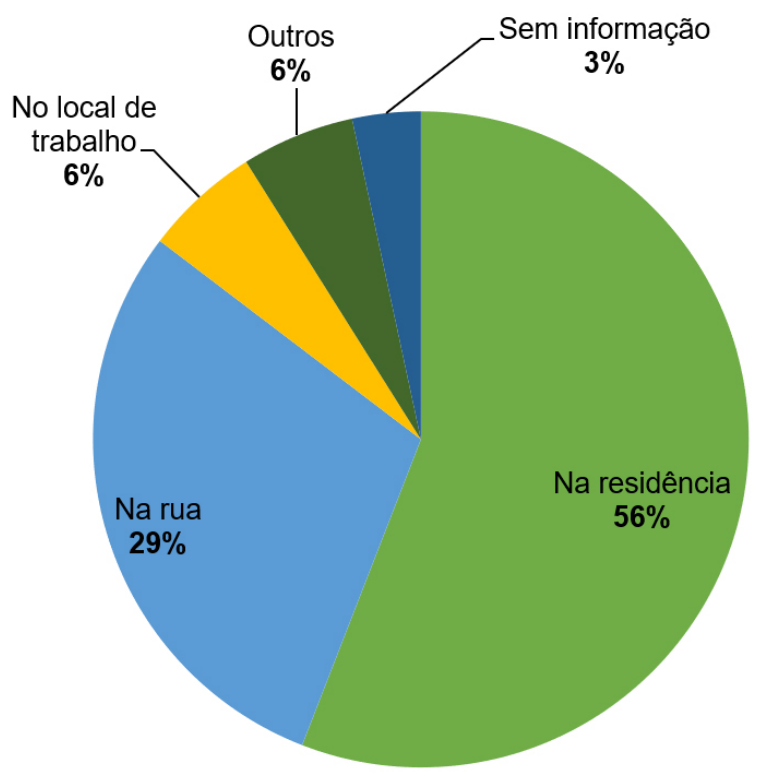

Fonte: CAERD/FUNPAPA, 2008-2017. 
Conforme Ribeiro (2009), o risco de uma mulher ser agredida por seu parceiro dentro do lar é aproximadamente nove vezes maior do que o risco de ser vítima de violência na rua. Nesse sentido, é importante salientar que enquanto os homens tendem a ser vítimas de violências praticadas em ambientes públicos, as mulheres, diariamente, sofrem com a violência dentro de suas próprias residências, muitas vezes, praticada por seus parceiros e ex-parceiros, evidenciando ser o lar o principal espaço onde este fenômeno se manifesta, portanto, o local mais inseguro para elas viverem (MADUREIRA et al., 2014, p. 605).

Por sua vez, as mulheres acolhidas apresentam uma diversidade de representações das possíveis motivações para essas práticas, dentre elas, o ciúme com 30\% dos registros, seguido pelo uso de drogas, $20,5 \%$ dos relatos, sendo mencionados também a recusa sexual, problemas com filhos, não aceitação do fim do relacionamento, dentre outros. Essa forma de perceber das mulheres acolhidas na Casa Abrigo vai ao encontro da pesquisa do DataSenado (2013), onde informa que $28 \%$ das mulheres creditam ao ciúme o principal motivo da agressão, enquanto $25,4 \%$ ao uso de álcool, 6,2\% a traição conjugal, $6 \%$ a separação, 2,6\% ao uso de drogas. Desconsideram, portanto, serem esses fatores desencadeadores da violência que tem sua verdadeira raiz nas tensões de gênero, de poder patriarcal historicamente construído.

Segundo Ferreira-Santos (2011), a cultura latina costuma vincular ao sentimento de ciúme uma manifestação clara de amor e cuidado entre parceiros de um relacionamento afetivo. Contudo, esse sentimento pode esconder uma tentativa de controle e aprisionamento do outro, suprimindo sua liberdade e desejos, assumindo, então, a forma de ciúme patológico, frequentemente relacionado aos casos de violência contra os parceiros (CENTEVILLE; ALMEIDA, 2007). Essa aparência do fenômeno, o ciúme, esconde a essência que está relacionada à reprodução social dos elementos que representam o patriarcado, tais como a não autonomia da mulher em relação ao seu corpo. 
Na literatura científica, o uso abusivo de álcool e outras drogas também é recorrentemente relacionado ao cometimento de atos violentos contra mulheres. Alguns pesquisadores argumentam o quanto se assemelham os comportamentos dos perpetradores de violência doméstica aos dos dependentes de substâncias psicoativas, incluindo a perda de controle, manutenção do comportamento apesar das consequências adversas (danos físicos e impactos nas relações familiares), culpabilização dos outros, negação, minimização e ciclo de progressivo aumento, seguidos por contrição e promessas de mudança, entre outros (ZILBERMAN; BLUME, 2005). Enfatiza-se que o álcool é um fator que tende a antecipar e agravar a violência, contudo, não pode ser considerado como sua causa primária. Dessa forma, homens que violentam mulheres não podem explicar seus atos exclusivamente pelo consumo do álcool e/ou drogas (MADUREIRA et al., 2014).

Outro dado de extrema relevância é a relação e convivência com o autor da violência. Dentre as 490 mulheres analisadas, 50,8\% mantinham união estável com seus companheiros, 31,6\% eram solteiras, $12 \%$ casadas, 3,7\% divorciadas, $0,4 \%$ viúvas e 1,5\% não informou. Nessa perspectiva, o balanço de 2016 da Central de Atendimento à Mulher informa que, dos 140.350 relatos de violência realizados no período, em $65,91 \%$ dos casos, foram cometidas por homens com quem as vítimas têm ou tiveram algum vínculo afetivo: atuais ou ex-companheiros, cônjuges, namorados ou amantes das vítimas.

Ao analisar a relação da mulher com o autor da violência sofrida, observa-se que 59,4\% sofreram violência de companheiros, 22,5\% de ex-marido/ex-companheiro/ex-namorado, 9\% foram vitimadas por maridos, 6,5\% por outros, como pai, irmão, namorado, vizinho, etc., e 2,6\% não informaram. O elevado número de agressores ex-parceiros indica a incapacidade de muitos homens em lidar de forma saudável com o processo de separação conjugal, especialmente quando a decisão parte unilateralmente da parceira, persistindo um sentimento de posse vinculado ao machismo e outras práticas histórica e socialmen- 
te construídas, tendo no patriarcado a principal base de sustentação. Quanto ao tempo em que vivenciaram a situação de violência, observa-se uma grande variação, mas o maior quantitativo está na faixa de 01 a 02 anos, 22,4\% do total. Segundo dados do Senado Federal/ ILB (s.d.), essa atitude é explicada a partir da análise do contexto da violência, sendo que muitos fatores podem contribuir para que a muIher permaneça em um relacionamento abusivo, entre eles, por estar inserida no ciclo de violência, sob ameaça, dependência financeira, a preocupação com a educação dos filhos, vergonha de se separar e de admitir que é agredida, por acreditar ser a última vez, entre outras. Cenário fortemente vinculado ao processo de desigualdade de gênero e na defesa de um processo de reprodução social alinhado "a valores tradicionais em torno [...] de um modelo conservador de família heteropatriarcal" (CISNE; SANTOS, 2018, p. 115).

Referente à periodicidade das violências sofridas, de acordo com Carvalho e Oliveira (2016), a incidência (frequência) da violência, às vezes, é subexplorada nos estudos da temática. Esses autores compreendem que aquelas mulheres que reportaram terem sofrido violência com uma frequência de "Às vezes", "Frequentemente" ou "Sempre", pertencem a um grupo de "incidência considerável" de violência doméstica. Assim, chama atenção o percentual expressivo de mulheres convivendo frequentemente em situações de violência, $64 \%$, e $26 \%$ eventualmente, todas em um círculo vicioso com constantes episódios violentos.

Outro dado apontado no resultado da pesquisa foi que, dentre as mulheres acolhidas, $57 \%$ verbalizaram não terem realizado exame de corpo de delito, 39\% realizaram e $4 \%$ não informaram. Isso implica dizer que muitas mulheres agredidas fisicamente não realizam esse importante procedimento. Nessa perspectiva, estudos demonstram a existência de um verdadeiro conflito das mulheres, pois ao mesmo tempo que desejam denunciar, relutam por vários motivos, como a dependência financeira ou emocional, a preocupação com os filhos, o 
medo de ser morta, a pressão externa da família ou religião em preservar a família, entre outras situações (RAMOS, 2010; SOUZA, 2009).

Considere-se também o fato de que muitas agressões físicas não deixam marcas aparentes, o que inviabiliza o exame de corpo de delito ${ }^{11}$. Destarte, o tempo de acolhimento de 20 dias se estabelece como característica frequente do serviço. Maués (2006) enfatiza que as muIheres que ficam por um tempo maior, geralmente, são as que estão com os laços de parentesco completamente dilacerados - em decorrência do isolamento de sua família, imposto pelo agressor - e não têm para onde ir, ao serem desligadas, o que se mostra uma dificuldade pelo fato da CAERD não dispor da retaguarda de uma política habitacional para essas mulheres.

Outro dado importante se refere aos desligamentos ${ }^{12}$, sendo $61 \%$ a pedido da própria acolhida, 34\% por parecer da equipe técnica, ou seja, após o deferimento das medidas protetivas e a ciência dos envolvidos, e $5 \%$ foram desligadas por outros motivos, tais como transferência para outra unidade de acolhimento. Segundo Maués (2006), existe um comportamento conflituoso entre algumas acolhidas que, apesar de se sentirem ameaçadas por seus companheiros agressores, pensam em sair da Casa Abrigo, preocupando-se com eles por não saberem onde estão, pelo medo de como se dará seu reencontro, e por quererem saber se estão bem cuidados. Nesse sentido, apenas $18 \%$ retornaram às suas residências sem a companhia do agressor, $48,8 \%$ para residência de familiares, $12 \%$ para residências de terceiros, 4,5\% para outras residências sem o agressor, 3,5\% foram transferidas para outro espaço, entretanto, $7,1 \%$ retornaram às suas residências e ao convívio com o agressor, para $6,1 \%$ não foi possível identificar o destino pós-desacolhimento. Para essas mulheres, esse constitui um momento dos mais difíceis, pois, agravados por suas condições financeiras desfavoráveis, acabam se submetendo a uma dependência abusiva ou retornando à casa de familiares que, muitas vezes, não estão preparados para o acolhimento e, por vezes, culpabilizando-as ainda mais. 


\section{Considerações finais}

A análise realizada apresenta de forma sintética alguns resultados da pesquisa empreendida pelo SEVISA e CAERD. A violência doméstica e familiar contra a mulher assume diversas facetas e envolve um caleidoscópio de perguntas e respostas. Assim, torna-se impossível que esse estudo encerre com afırmações imutáveis e indiscutíveis. Dentre os resultados possíveis, constatou-se a existência de alguns padrões e o delineamento de um perfil, ainda que inaugural. Reforça-se o caráter arquétipo dessas informações, havendo outras variáveis envolvidas e já analisadas ao longo deste estudo. Nesta perspectiva, do total de mulheres atendidas, $70 \%$ pardas, $11,4 \%$ negras, 17,6\% brancas. Esse dado nos traz o questionamento acerca da raça/cor, tendo em vista a construção histórica e estrutural do racismo na sociedade brasileira que contribui para a difıculdade de identificação/representatividade. Podemos concluir que aproximadamente $80 \%$ das mulheres em situação de violência, atendidas pela CAERD, são negras. Com relação à renda, 54,1\% não possuem, e a grande maioria reside em áreas periféricas da cidade.

Construir uma sociedade enraizada nos Direitos Humanos e na equidade de gênero são objetivos que devem sempre mover as políticas públicas. As mulheres brasileiras ainda são forjadas em um contexto altamente excludente, logo, marcado por desproteções sociais ao longo de suas trajetórias pessoais. O enfrentamento de tal cenário não pode se dar às escuras, tateando em um solo desconhecido. É necessário aclarar o fenômeno da violência doméstica e familiar contra a mulher para, a partir daí, escolher caminhos e estratégias mais coerentes e produtivas pautados na luta dos movimentos sociais. Para compreender as múltiplas determinações do fenômeno ora analisado, verificou-se a importância das categoriais de gênero, raça e classe, tendo em vista os principais resultados apresentados.

O universo de dados aqui analisados sobre a barbárie da violência doméstica e familiar contra a mulher demonstra a necessidade primordial da elaboração de estratégias conjuntas, envolvendo o Esta- 
do, por meio das políticas públicas e seus agentes, sociedade civil e movimentos sociais. Cada pessoa e instituição têm o dever ético-político de contribuir na construção de um mundo com mais igualdade de gênero e cidadania. Dentre as medidas necessárias, sublinha-se a importância do amplo debate e a consequente desconstrução e construção de princípios pautados na garantia dos direitos humanos para as mulheres. Finaliza-se sinalizando para que a condução das políticas públicas voltadas às mulheres esteja embasada, entre outros pressupostos, no conhecimento das realidades vivenciadas por elas, bem como pautadas na livre participação em todos os seus momentos de elaboração e execução.

\section{Referências}

CARVALHO, José; OLIVEIRA, Victor. Pesquisa de Condições Socioeconômicas e Violência Doméstica e Familiar contra a Mulher: Prevalência da Violência Doméstica e o Impacto nas Novas Gerações. Relatório Executivo I - Primeira Onda - 2016. Versão 2.4.

CENTEVILLE, Valéria; ALMEIDA, Thiago. Ciúme romântico e a sua relação com a violência. Psic. Rev., São Paulo, v. 16, n. 1 e n. 2, 73-91, 2007.

CISNE, Mirla; SANTOS, Silvana. Feminismo, diversidade sexual e serviço social. São Paulo: Cortez, 2018.

DATASENADO. Violência Doméstica e Familiar Contra a Mulher. Secretaria de Transparência, Brasil, 2013.

DINIZ, Normélia; SANTOS, Maria; LOPES, Regina. Representações sociais da família e violência. Rev Latino-Am Enfermagem, 2007, novembro-dezembro, 15(6).

ECHEVERRIA, Jasmin. Relações entre mulheres trabalhadoras e violência doméstica: percepções de mulheres atendidas em um Centro de Atendimento à Mulher. Dissertação (Mestrado) - Escola Nacional de Saúde Pública Sérgio Arouca, Rio de Janeiro, 2016.

ECHEVERRIA, Jasmin; OLIVEIRA, Maria; ERTHAL, Regina. Violência doméstica e trabalho: percepções de mulheres assistidas em um Centro de Atendimento à Mulher. Saúde Debate, Rio de Janeiro, v. 41, n. Especial, p. 13-24, Jun. 2017. 
FERREIRA-SANTOS, Eduardo. Sobre o ciúme. Revista Brasileira de Psicodrama, v. 19, n. 1, São Paulo, 2011.

INSTITUTO DE PESQUISA ECONÔMICA APLICADA - IPEA; FÓRUM BRASILEIRO DE SEGURANÇA PÚBLICA - FBSP. Atlas da violência. Rio de Janeiro: IPEA; FBSP, 2018.

JONG, Lin; SADALA, Maria; TANAKA, Ana. Desistindo da denúncia ao agressor: relato de mulheres vítimas de violência doméstica. Rev Esc Enferm USP, 2008, 42(4), p. 744-751.

LIMA, Rita de Lourdes. A questão das relações sociais de gênero em Marx e Engels: contribuições do pensamento marxista para entender a opressão das mulheres. In: BOSCHETTI, Ivanete; BEHRING, Elaine; LIMA, Rita de Lourdes de (org.). Marxismo, política social e direitos. 1. ed. São Paulo: Cortez, 2018.

LIMA, Vera; SILVA, Andrey. Conhecendo o Perfil e os Sentimentos de MuIheres Vítimas de Violência Atendidas na Delegacia Especializada de Atendimento à Mulher do Município de Belém. In: Gênero na Amazônia (Dossiê), Belém, n. 2, jul./dez., 2012.

MADUREIRA, Alexandra et al. Perfil de homens autores de violência contra mulheres detidos em flagrante: contribuições para o enfrentamento. Escola Anna Nery, v. 18, n. 4, Rio de Janeiro, Oct./Dec., 2014.

MAUÉS, Sandra. Feminismos e políticas governamentais: um estudo sobre o Albergue Emanuelle Rendeiro Diniz. Dissertação (Mestrado em Serviço Social) - Centro Sócio-Econômico, Universidade Federal do Pará, Belém/PA, 2006.

MINAYO, Maria Cecília. O desafio do Conhecimento: pesquisa qualitativa em Saúde. 12. ed. São Paulo: Hucitec, 2010.

MÉSZÁROS, István. Para além do Capital. São Paulo. Boitempo. 2002.

ORGANIZAÇÃO PAN-AMERICANA DA SAÚDE; ORGANIZAÇÃO MUNDIAL DA SAÚDE. Violência contra a mulher: Estratégia e Plano de Ação para o Reforço do Sistema de Saúde para Abordar a Violência Contra a Mulher. 2015.

PEREIRA, Paula. Mulheres em situação de violência: percepções sobre a perpetuação da violência em suas vidas. Dissertação (Mestrado) - Programa de Pós-Graduação em Ciências da Saúde, Faculdade de Medicina, Universidade Federal de Goiás, Goiânia, 2017. 
RAMOS, Maria. Histórias de "mulheres": a violência vivenciada singularmente e a Lei 11.340 como possível recurso jurídico. Dissertação (Mestrado) - Programa de Pós-Graduação em Psicologia, Universidade Federal de Santa Catarina, Florianópolis, 2010.

RIBEIRO, Tatiana. Violência entre parceiros íntimos nos primeiros cinco meses de pós-parto em usuárias de unidades básicas de saúde do Rio de Janeiro. Dissertação (Mestrado) - Instituto de Medicina Social, Universidade do Estado do Rio de Janeiro, 2009.

SAFFIOTI, Heleieth. Contribuições feministas para o estudo da violência de gênero. Cadernos Pagu, 2001, p. 115-135.

SAFFIOTI, Heleieth. Gênero, Patriarcado e Violência. São Paulo: Fundação Perseu Abramo, 2004.

SAFFIOTI, Heleieth. Já se mete a colher em briga de marido e mulher. São Paulo em Perspectiva (online), 1999, v. 13, n. 4, p. 82-91.

SENADO FEDERAL/INSTITUTO LEGISLATIVO BRASILEIRO. Dialogando sobre a Lei Maria da Penha. Cadernos EAD-ILB, s.d.

SOUZA, Maria. Violência contra mulheres: uma questão de gênero - Montes Claros 1985-1994. Dissertação (Mestrado em História) - Universidade Federal de Uberlândia, 2009.

SOUZA, Nilde; MORAES, Roseana. Albergue de Mulheres Emanuelle Rendeiro Diniz: do pranto se faz o canto. In: A Política de Assistência Social em Belém, Volume II. Belém: FUNPAPA, 2004.

TOLOSA, Tatiane. Violência de Gênero: Caracterização do Feminicídio no Município de Belém. Dissertação (Mestrado) - Programa de Pós-graduação em Segurança Pública, Instituto de Filosofia e Ciências Humanas, Universidade Federal do Pará, Belém-PA, 2017.

WAISELFISZ, Julio. Mapa da Violência 2015: Homicídio de mulheres no Brasil. 1. ed. Brasília/DF: 2015.

ZILBERMAN, Monica; BLUME, Sheila. Violência doméstica, abuso de álcool e substâncias psicoativas. Rev Bras Psiquiatr., 2005, 27(Supl II), p. S51-S55. 


\section{Notas}

1 Especialista em Instrumentos e Técnicas do Serviço Social. Assistente Social. Coordenadora da Vigilância Socioassistencial da Fundação Papa João XXIII - FUNPAPA, Belém/PA, Brasil. Servidora pública efetiva. ORCID: 0000-0003-0448-9678. E-mail: celiagborges@globo.com

2 Mestre em Economia pelo Programa de Pós-Graduação em Economia da Universidade Federal do Pará - UFPA. Economista na Fundação Papa João XXIII - FUNPAPA, Belém/PA, Brasil. Servidora pública efetiva. ORCID: 0000-00030160-9881. E-mail: milene.lucas@hotmail.com

3 Mestre pelo Programa de Pós-Graduação em Sociologia e Antropologia - PPGSA da UFPA. Antropólogo na Fundação Papa João XXIII - FUNPAPA, Belém/ PA, Brasil. Servidor público efetivo. ORCID: 0000-0001-9090-7498. E-mail: paulo19mec@yahoo.com.br

4 Mestre em Serviço Social pelo Programa de Pós-Graduação em Serviço Social - PPCSS da UFPA. Doutoranda do PPCSS/UFPA. Assistente Social na Fundação Papa João XXIII - FUNPAPA, Belém/PA, Brasil. Servidora pública efetiva. ORCID: 0000-0003-4485-6508. E-mail: cassiabarbosa.social@gmail.com

5 Segundo a NOB/SUAS, a Vigilância Socioassistencial constitui uma das funções da política de assistência social, devendo ser realizada por meio da produção, sistematização, análise e disseminação de informações territorializadas, tratando das situações de vulnerabilidade e risco que incidem sobre famílias e indivíduos e dos eventos de violação de direitos em determinados territórios; do tipo, volume e padrões de qualidade dos serviços ofertados pela rede socioassistencial, entre outras atribuições.

6 As informações dos prontuários das mulheres foram sistematizadas pela equipe técnica responsável pelo atendimento direto, e repassadas à Vigilância Socioassistencial de forma agregada, em tabelas, sendo resguardado o sigilo dos atendimentos.

7 O corte temporal teve por objetivo atingir os dez (10) últimos anos, já dentro da Política Nacional de Assistência Social ora em vigência.

8 O Mapa da Violência: Homicídio de mulheres no Brasil (WAISELFISZ, 2015) é uma das poucas fontes de dados oficiais que apresenta informações em nível municipal.

9 Segundo Souza e Moraes (2004), o espaço de acolhimento recebeu o nome de Emanuelle Rendeiro Diniz como forma de homenagear a adolescente que aos 14 anos de idade foi raptada por dois homens em uma parada de ônibus no bairro do Benguí, na cidade de Belém, sendo violentada física, sexualmente e morta, em 24 de junho de 1992, tragédia com grande repercussão local, gerando o acirramento da luta dos movimentos de mulheres pelo fim desse tipo de violência. 
10 Observa-se que Belém tem papel de destaque na trajetória do enfrentamento à violência doméstica contra a mulher, pois foi onde ocorreu, em 1994, a Convenção Interamericana para Prevenir, Punir e Erradicar a Violência contra a Mulher, conhecida como Convenção de Belém do Pará.

11 Ressalta-se que a maioria das usuárias atendidas pela CAERD (98\%) foi encaminhada pela Delegacia Especializada no Atendimento à Mulher-DEAM que, após procedimentos legais e não havendo possibilidade de local seguro para ficarem, direciona-as ao Espaço de Acolhimento.

12 Está relacionado à saída da mulher em situação de violência do espaço de acolhimento. 


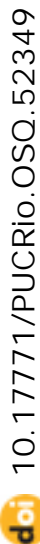

